\title{
O QUE FAZ UMA PSICOLOGIA SOCIAL? INTERVENÇÃO NA
} PSICOLOGIA SOCIAL BRASILEIRA

\author{
¿QUÉ HACE UNA PSICOLOGÍA SOCIAL? INTERVENCIÓN EN \\ PSICOLOGÍA SOCIAL BRASILEÑA \\ WHAT MAKES A SOCIAL PSYCHOLOGY? INTERVENTION IN SOCIAL \\ PSYCHOLOGY BRAZILIAN
}

http://dx.doi.org/10.1590/1807-03102015aop002

Leidiane Pereira Lopes e Adriano Roberto Afonso do Nascimento Universidade Federal de Minas Gerais, Belo Horizonte/MG, Brasil

\section{RESUMO}

Tema identificado como central desde as primeiras proposições abrapsianas, a intervenção tem se consolidado, na psicologia social brasileira, como um campo bastante diversificado quanto aos seus objetivos, públicos-alvo e procedimentos. Assim, a presente pesquisa teve como objetivo identificar e analisar o que foi considerado intervenção em 260 trabalhos completos publicados nos anais dos Encontros Nacionais da Associação Brasileira de Psicologia Social (ABRAPSO) realizados em 2007, 2009 e 2011. Dois procedimentos foram utilizados para o tratamento dos dados: Análise de Conteúdo e Análise Lexical. A discussão integrada dos resultados permitiunos um mapeamento de características que possibilitaram compreender o conjunto de atividades relatadas, tais como tipo de trabalho, sobressaindo-se os de Pesquisa, com 117 trabalhos; objetivos: Fazer, Analisar, Conhecer e Apresentar; alvo principal, sobressaindo-se Trabalhadores/Profissionais; espaços/locais, sendo predominantes as Instituições de Saúde; e aspectos metodológicos, sobressaindo-se as Técnicas Grupais, bem como a construção de um "conceito" geral atribuído ao termo intervenção.

Palavras-chave: psicologia social; intervenção; abrapso; análise de conteúdo; análise lexical

\section{RESUMEN}

Identificado como tema central de las primeras proposiciones abrapsianas, la intervención se ha consolidado, en la psicología social brasileña, como un campo muy diverso en cuanto a sus metas, público y procedimientos. Por lo tanto, esta investigación tuvo como objetivo identificar y analizar lo que se consideraba la intervención en 260 trabajos completos publicados en los anales de los Encuentros Nacionales de la Asociación Brasileña de Psicología Social realizados en 2007, 2009 y 2011. Para el tratamiento de datos: Análisis de Contenido y Análisis Léxico. La discusión integrada de los resultados permitió mapear características que ayudaran entender el conjunto de actividades declarada, tales como el tipo de trabajo, destacándose la Investigación , con 117 trabajos; objetivos: hacer, analizar, conocer y presentar; objetivo principal, destacándose los Trabajadores/Profesionales; espacios/lugares, siendo las Instituciones de Salud predominantes; y aspectos metodológicos, destacándose las Técnicas de Grupo, así como la construcción de un "concepto" general asignado a lo término "intervención".

Palabras clave: psicología social; intervención; ABRAPSO; análisis de contenido; análisis léxico

\begin{abstract}
Identified as a central theme since the first ABRAPSO's propositions, the intervention has been consolidated, in the Brazilian social psychology, as a field quite diverse as to its objectives, target audiences and procedures. Thus, the present research aimed to identify and analyze what was considered intervention in 260 full papers published in the proceedings of the Associação Brasileira de Psicologia Social (ABRAPSO) conducted in 2007, 2009 and 2011. Two procedures were used for the treatment of the data: Content Analysis and Lexical Analysis. The integrated discussion of the results allowed us a mapping of features that made possible to understand the set of reported activities such as type of work, standing out Research, with 117 papers; goals: Do, Analyze, Know and Introduce; the main target, standing out Workers/Professionals; spaces/places, being predominant the health institutions; and methodological aspects, standing out Group Techniques, as well as the construction of a general "concept " given the term intervention.
\end{abstract}

Keywords: social psychology; intervention; abrapso; content analysis; lexical analysis 


\section{Introdução: contradições e origem do problema}

Em pesquisa realizada acerca do trabalho do psicólogo no Brasil, Gondim, Bastos e Peixoto (2010) observaram, no capítulo dedicado às áreas de atuação, atividades e abordagens teóricas do psicólogo brasileiro, que, embora as áreas clínica e de avaliação psicológica continuem sendo as principais áreas de atuação na psicologia em nosso país, “indícios apontam que o modelo de intervenção individual está sendo substituído por outro modelo, mais fortemente focado na intervenção social” (p. 192). Segundo os referidos autores, esse novo modelo pode ser visto em diversas áreas de atuação, bem como está apoiado em um conjunto também diverso de atividades e abordagens teóricas.

Entretanto, no mesmo relato, os autores identificam um descompasso entre essa recente tendência à intervenção social e a formação em psicologia no nosso país. Conforme salientam, "o perfil encontrado ainda é o mesmo das pesquisas realizadas há décadas: o psicólogo brasileiro ainda tem uma formação eminentemente clínica, com defasagem de competências para a atuação em organizações e em processos grupais" (Gondim, Bastos, \& Peixoto, 2010, p. 398).

Nesse sentido, em pesquisa realizada anteriormente, sobre o lugar da psicologia social na formação dos psicólogos, Souza e Souza (2009) avaliam que "atualmente, a área de psicologia social vive uma situação de dúvida e ampliação de busca de recortes de objeto a considerar, de formulações teóricas a serem feitas, de métodos de trabalho e modos de inserção profissional" (p. 385). A partir de levantamento feito junto a professores de psicologia social em diferentes universidades das diversas regiões brasileiras, assim como com base na análise de ementas e de programas e bibliografias utilizadas por tais professores, os autores constataram que o ensino da psicologia social no Brasil se organiza prioritariamente em torno de tópicos da área, o que indica uma "tendência geral dos professores de apresentarem a disciplina a partir de conceitos descritivos/fenômenos da Psicologia Social" (Souza \& Souza, 2009, p. 388).

Além disso, de acordo com Souza e Souza (2009), os métodos e as práticas tiveram baixa representatividade quando comparados a outras categorias como: premissas, correntes teóricas e conceitos descritivos/fenômenos. A partir disso, os autores concluem que "os baixos índices de métodos e das práticas podem indicar que os aspectos de aplicação da Psicologia Social não são valorizados na determinação do conteúdo das disciplinas" (Souza \& Souza, 2009, p. 388).

Todavia, como nos aponta Moreira (2007), é possível verificar nas três últimas décadas uma aproximação da prática de pesquisa e de intervenção da psicologia social com o cotidiano dos grupos concretos, tais como as instituições, as organizações, os movimentos sociais e políticos. Em um levantamento realizado durante uma disciplina de psicologia social, a autora solicitou aos estudantes do curso de psicologia algumas palavras referentes à concepção desses alunos acerca do que viria a ser a psicologia social. Algo que se destacou foi o fato de os alunos terem considerado a psicologia social como "uma psicologia que visa fazer intervenções no meio social, para 'ajudar' as classes menos favorecidas" (Moreira, 2007, p. 60). Com base nisso, a autora afirma que

a psicologia social produziu, sem dúvida, metodologias para a intervenção em grupos e comunidades das periferias das grandes cidades. Buscou apreender os sentidos construídos por esses grupos e comunidades para a sua vida cotidiana, fazendo um movimento de incluir esses grupos e suas questões como objeto de pesquisa e intervenção, com a intenção ética explícita de contribuir para a transformação da sociedade. (Moreira, 2007, p. 60)

Contudo, uma carência de trabalhos dedicados a sistematizar essas contribuições e a fundamentar as atuais práticas tem sido observada e apontada como problemática, haja vista a coexistência de um discurso que anuncia uma nova perspectiva com a constatação de que faltam teorizações e formação específica que a fundamente. Quer dizer, fala-se em intervenção em psicologia social, reconhece-se sua importância para a psicologia social brasileira, mas faltam elementos que permitam sustentar qual a especificidade dessa intervenção realizada no cotidiano dos trabalhos em psicologia social.

Diante disso, parece oportuno a disponibilização de informações relativas ao que vem sendo realizado no campo. De modo mais específico, informações que possibilitem explicitar e sistematizar os elementos que têm norteado a aplicação e o fazer da psicologia social no Brasil.

Considerando aspectos relativos à história da psicologia social (Camino \& Torres, 2011; Farr, 1998; Ferreira, 2011), podemos enfatizar que, em âmbito internacional, a psicologia social se desenvolveu majoritariamente como uma ciência experimental, sendo a pesquisa de laboratório seu maior enfoque. Porém, no período pós-guerra, identificado na área 
como um período de mudança no que diz respeito aos seus aspectos teórico e ideológico, diversas iniciativas foram tomadas no sentido de compreender as mazelas oriundas da guerra, como também de encontrar e desenvolver soluções para as problemáticas sociais vivenciadas em tal período. Esse momento, considerado por alguns autores, como Camino e Torres (2011), como de transição, ficou marcado, no que concerne à pesquisa, pela busca por temas de "relevância social", e no que concerne à prática, pela busca de resolução dos problemas sociais. Dito isso, podemos identificar, no referido período, um primeiro movimento na área em direção à aplicação das pesquisas, considerandose explicitamente seus aspectos prático e interventivo.

Em âmbito nacional, podemos dizer que o interesse por aspectos relativos à intervenção é recente, admitindo-se que é apenas em 1980 que a psicologia social no Brasil tem, com a fundação da Associação Brasileira de Psicologia Social ABRAPSO, a formalização de seu interesse mais explícito pela realidade brasileira e pelo enfretamento das problemáticas vivenciadas pelo país. É nesse período que, influenciada também pelas lutas travadas por diversos movimentos sociais contra a ditadura militar no Brasil, a psicologia social vivencia o que hoje reconhecemos ter sido uma crise no que tange à relevância social dessa área.

Essa crise de relevância da psicologia social, dentre outras coisas, fez com que a área se questionasse acerca de seu papel ideológico, histórico e político, bem como acerca de seus efeitos na atuação profissional e na produção científica no contexto específico da realidade brasileira. Uma das saídas para essa crise foi a adoção de novas perspectivas teóricas e metodológicas até então pouco utilizadas ou até mesmo desconsideradas na psicologia social, tais como a pesquisa ação e a pesquisa participante, dentre outras, objetivando a construção de um saber pautado na realidade do nosso país.

Além disso, um saber dedicado a dar à psicologia social um caráter aplicado em ações voltadas para a intervenção em comunidades e organizações, a fim de minimizar as desigualdades sociais (Bomfim, 2003; Lane \& Bock, 2003; Tatsch, Guareschi, \& Baumkarten, 2009; Neiva \& Torres, 2011). Conforme Tatsch, Guareschi e Baumkarten (2009), a importância da ABRAPSO reside justamente no fato de ela viabilizar um grande espaço de trocas, críticas e invenção de novas formas de combate às injustiças e desigualdades sociais, posicionando-se de forma ética, política e socialmente comprometida com as intervenções profissionais, que devem ser conduzidas em prol da afirmação da vida, da legitimidade da diferença e do compromisso com seu tempo e sua história.
Nesse sentido, Neiva (2010) identifica que, "embora as necessidades psicossociais tenham sempre existido nos indivíduos, grupos e sociedades, é relativamente recente a constituição de uma área específica da psicologia que dê suporte teórico e metodológico para a realização de intervenções psicossociais" (p. 13). Intervenções psicossociais estão associadas, para a autora, à busca de bem-estar psicossocial dos indivíduos, grupos e comunidades, assim como à busca de transformação, mudança, pesquisa e ação.

Conforme aponta, a intervenção psicossocial se constituiu como uma área de estudo que surgiu na segunda metade do Século XX na interface entre a psicologia clínica e a psicologia social. Em suas palavras,

de um lado, o método psicanalítico conseguiu quebrar a compartimentação existente entre a pesquisa fundamental e a pesquisa aplicada e contribuir, assim, para uma pesquisa e prática transformadoras. De outro lado, o conceito de pesquisa ativa, introduzido por Lewin, reforçou a necessidade da complementaridade entre a pesquisa e ação e a importância de se pesquisar sobre as situações da vida corrente, saindo dos laboratórios. (Neiva, 2010, pp. 13-14)

Apartir disso, a autora considera que a intervenção psicossocial segue os princípios do método científico ao mesmo tempo que une pesquisa à ação. "A pesquisa permeia todo o processo, desde a análise da demanda e o mapeamento das necessidades psicossociais até a etapa final de avaliação da intervenção. É esse caráter científico que produz reflexão, crítica e reformulação" (Neiva, 2010, p. 16). Com isso, a autora compreende a intervenção psicossocial como um processo científico a partir do qual se constrói conhecimento acerca de determinada realidade ao mesmo tempo que se atua sobre essa realidade a fim de transformá-la. Desse modo, a intervenção psicossocial se configuraria em um processo de interação do sujeito com o meio ambiente com vistas à mudança no sentido de desenvolvimento de uma dada realidade.

Considerando, assim, a importância que a intervenção foi adquirindo ao longo do desenvolvimento da psicologia social em seu âmbito internacional e nacional, bem como a carência de trabalhos dedicados a sistematizar as atuais intervenções que vêm sendo realizadas, a proposta do presente estudo foi identificar, sistematizar e analisar o que tem sido apontado como intervenção em psicologia social, como também problematizar de que forma se configuram os relatos em torno do fazer, da prática em psicologia social.

Para isso, optou-se por um estudo exploratório que consistisse na busca pelos significados dados à 
intervenção em produções disponíveis naquela que é, possivelmente, a maior base de centralização e disseminação de pesquisas científicas atualizadas no âmbito da psicologia social brasileira, a saber, os anais dos Encontros Nacionais da Associação Brasileira de Psicologia Social - ABRAPSO.

A escolha pelas produções escritas oriundas dos três últimos Encontros Nacionais da ABRAPSO relaciona-se ao papel que essas produções ocupam na divulgação do que tem sido investigado, problematizado e realizado pela área em um período recente. Os Encontros, como o nome diz, são espaços de trocas e de debates, nos quais se divulga e se discute o conhecimento que tem sido produzido. Os anais refletem tais debates, haja vista serem compostos pelos trabalhos completos apresentados durante os eventos. Eles têm, dessa forma, o papel de tornar acessível, após o evento, o conhecimento que foi considerado importante e necessário de ser divulgado pela comunidade participante e organizadora do evento. Ademais, a ABRAPSO é, atualmente, a maior associação em psicologia social do país e organiza bienalmente o maior evento de psicologia social no Brasil, através do qual "resgata e consolida propostas de pesquisas e intervenções, agregando a ciência e a profissão" (Tatsch, Guareschi, \& Baumkarten, 2009, p. 11).

\section{Procedimentos de coleta e de análise de dados}

Foram analisados os trabalhos completos publicados nos anais dos 3 últimos Encontros Nacionais da ABRAPSO, referentes aos anos de 2007, 2009 e 2011. A escolha desses encontros pautou-se na totalidade dos trabalhos completos em formato digital disponíveis no sítio eletrônico da ABRAPSO e na recenticidade das pesquisas e intervenções realizadas e descritas nesses trabalhos completos.

O critério utilizado para a seleção dos referidos trabalhos foi a ocorrência do termo intervenção no corpo do texto em, pelo menos, duas frases, o que nos permitiu chegar a 260 trabalhos completos a serem analisados $(18,28 \%$ de um total de 1.422 trabalhos completos consultados). A delimitação da busca a partir desse critério foi importante porque, em muitos textos, o termo intervenção aparecia apenas uma vez, referindo-se somente a uma disciplina, laboratório ou item bibliográfico. Embora sejam formas interessantes de apresentação do termo, para os objetivos do presente estudo a simples aparição do termo não seria suficiente, haja vista que o nosso interesse não se reduziu a ocorrências e sim a significados em contextos específicos.

Como procedimento de tratamento de dados, foi escolhida, inicialmente, a análise de conteúdo (Bardin, 1977; Bauer, 2002; Vala, 2003), que nos possibilitou, a partir da construção a posteriori de categorias e tomando o tema como unidade de análise, identificar as características mais gerais das atividades descritas, como tipo de trabalho, objetivos, alvo principal, espaços/locais e aspectos metodológicos.

Contudo, o corpus não permitiu a apreensão de um elemento extremamente importante para o nosso estudo, qual seja, a própria definição formal de intervenção. Esse fato nos obrigou a pensar em outras estratégias metodológicas. Com o objetivo de identificarmos, na ausência de definições formais, os possíveis significados do termo intervenção no nosso corpus, reunimos todas as frases que continham o referido vocábulo e suas variantes nos textos selecionados e construímos um segundo corpus. Este segundo corpus foi submetido ao tratamento realizado pelo programa de Análise Lexical por Contexto de um Conjunto de Segmentos de Texto - ALCESTE ${ }^{1}$, cuja análise facultou a apreensão das diferentes formas de discurso presentes nos textos a respeito do objeto em questão, o termo intervenção, e, consequentemente, uma compreensão do seu "significado" nos textos analisados.

Conforme será possível observar na apresentação dos resultados a seguir, as classes obtidas a partir da análise ALCESTE permitiram a construção de um possível conceito para o termo intervenção no corpus analisado, de modo que a utilização desse método associada à análise de conteúdo nos possibilitou, no nosso entendimento, um tratamento mais abrangente do material selecionado.

\section{Resultados}

Iniciamos nossa apresentação com a distribuição dos 260 relatos que se referem à intervenção segundo as características predominantes deles: Pesquisa (117 trabalhos), Prática (108 trabalhos) e Teoria (35 trabalhos). A Figura 1 exibe a porcentagem de cada uma dessas categorias no universo total dos 260 trabalhos analisados. 
Figura 1 - Distribuição dos relatos de acordo com as categorias dos tipos de trabalho analisados

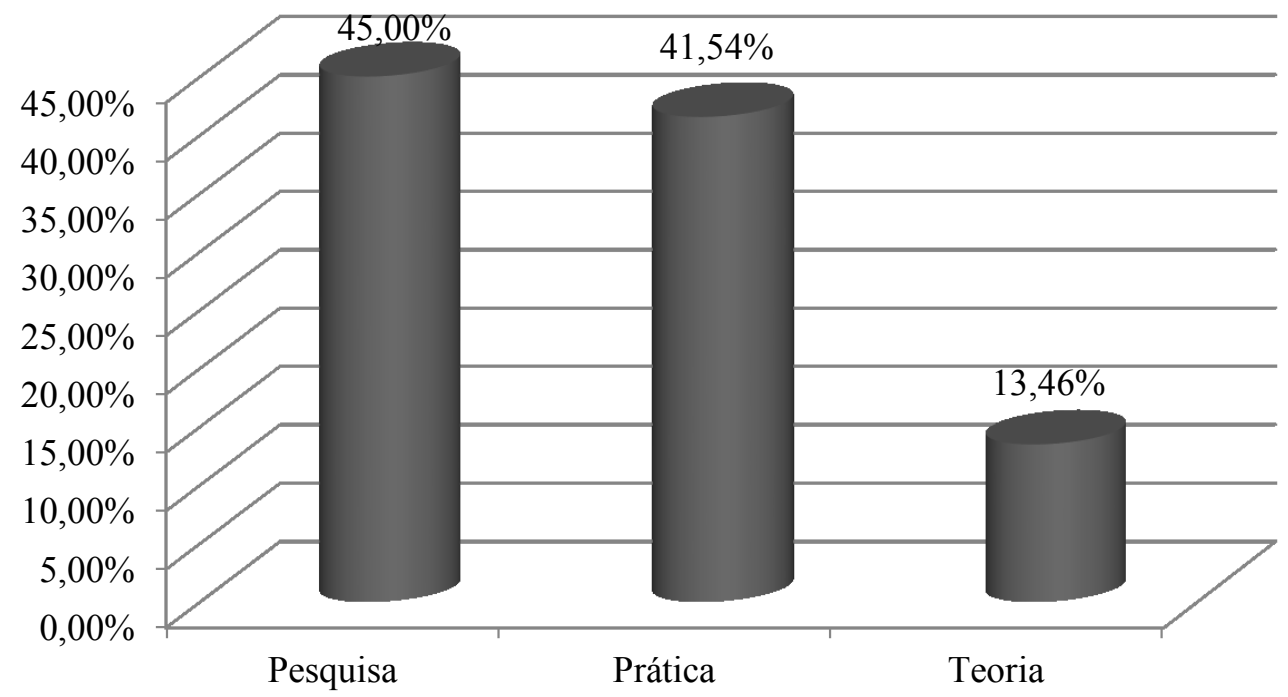

Podemos observar que o número maior de trabalhos que abordam de alguma forma o termo intervenção está associado à categoria Pesquisa. Em seguida, aparecem aqueles relativos à categoria Prática, com porcentagem um pouco inferior. Os trabalhos categorizados em Teoria aparecem com porcentagem bem abaixo.
Tendo categorizado os trabalhos conforme os seus tipos, apresentamos na Figura 2 os objetivos elencados pelos autores dos relatos analisados, os quais foram categorizados em 4 grandes blocos, a saber: Analisar (83 relatos), Apresentar (20), Conhecer (73) e Fazer (84).

Figura 2 - Comparativo dos objetivos presentes na amostra total

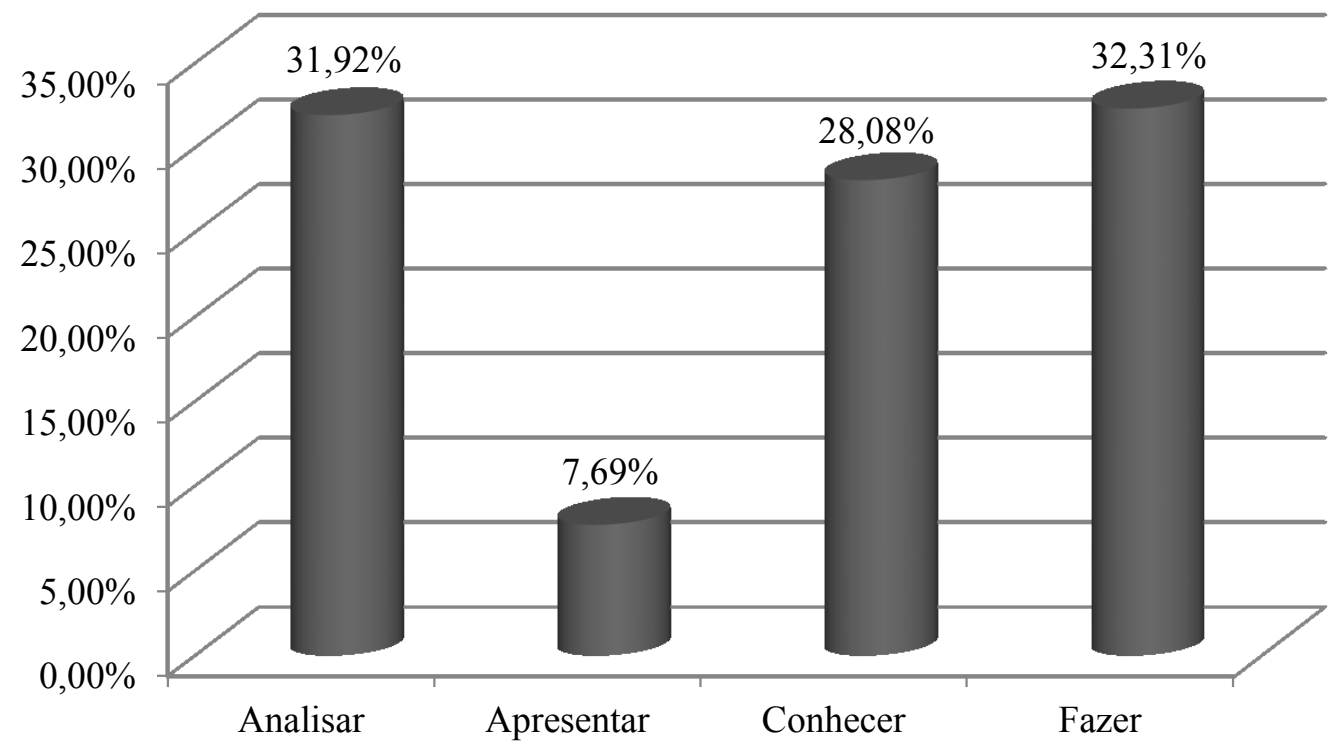


Vale destacar que se procurou, para tal categorização, o principal termo referente ao objetivo presente em cada texto.

Como é possível verificar na análise comparativa presente na Figura 2, Fazer aparece de forma mais expressiva nos objetivos dos trabalhos analisados, sendo seguido por Analisar, Conhecer e, por fim, Apresentar.
Identificamos, em seguida, o alvo principal apontado nos relatos analisados. Preferiu-se aqui considerar o termo alvo principal porque nem sempre o alvo do trabalho é um público. Assim, identificando alvo, contemplamos tanto pessoas, como instituições e temas, dentre outros. A distribuição geral do universo pesquisado, segundo o alvo principal das intervenções relatadas, pode ser verificada na Figura 3.

Figura 3 -Alvos principais de intervenção nos trabalhos analisados

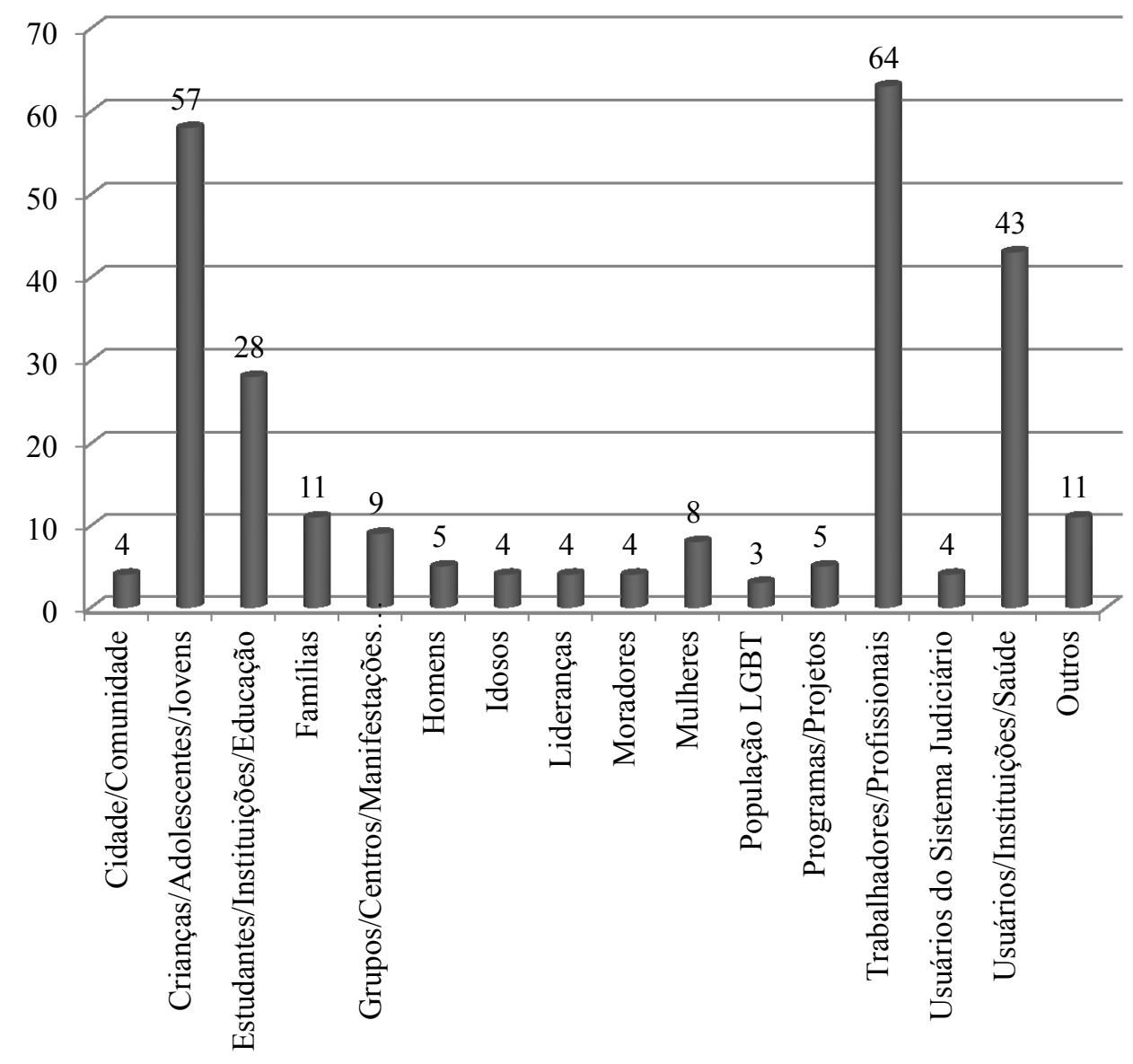

É interessante mencionar que Trabalhadores/ Profissionais aparecem como os alvos principais mais recorrentes, sendo seguidos por Crianças/ Adolescentes/Jovens e Usuários/Instituições/Saúde.
Complementando a caracterização dos trabalhos analisados, apresentamos, a seguir, os espaços/ locais onde foram desenvolvidas as ações de intervenção relatadas (Figura 4). 
Figura 4 - Espaços/locais nos quais os trabalhos analisados foram realizados

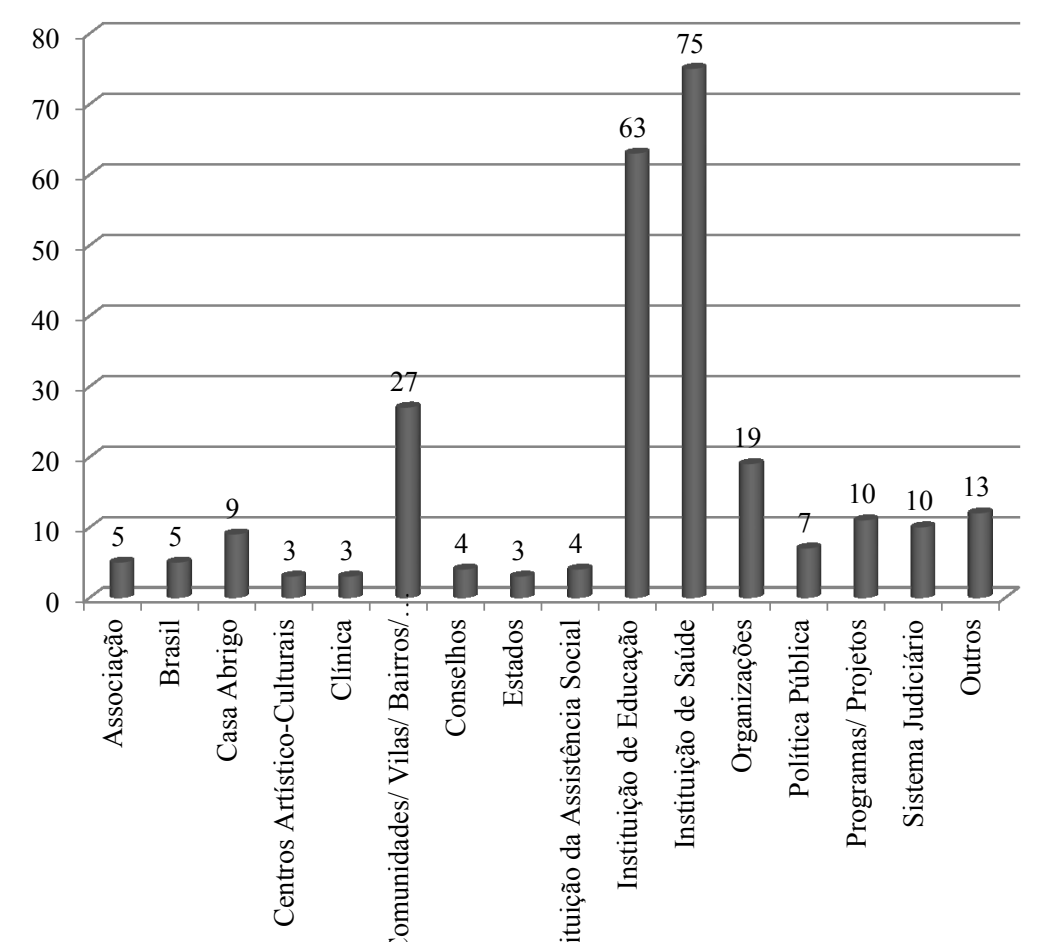

Aqui também vale destacar a escolha majoritária por Instituição de Saúde e, em seguida, por Instituição de Educação, acompanhando, em grande medida, a escolha pelos alvos principais presentes nesses espaços/locais.
Dos 260 trabalhos analisados, $185(71,15 \%)$ fazem referências explícitas aos procedimentos realizados, enquanto $75(28,85 \%)$ não o fazem. As referências foram categorizadas conforme a Figura 5. É importante observar que foram consideradas as

Figura 5 - Procedimentos metodológicos adotados nos trabalhos analisados

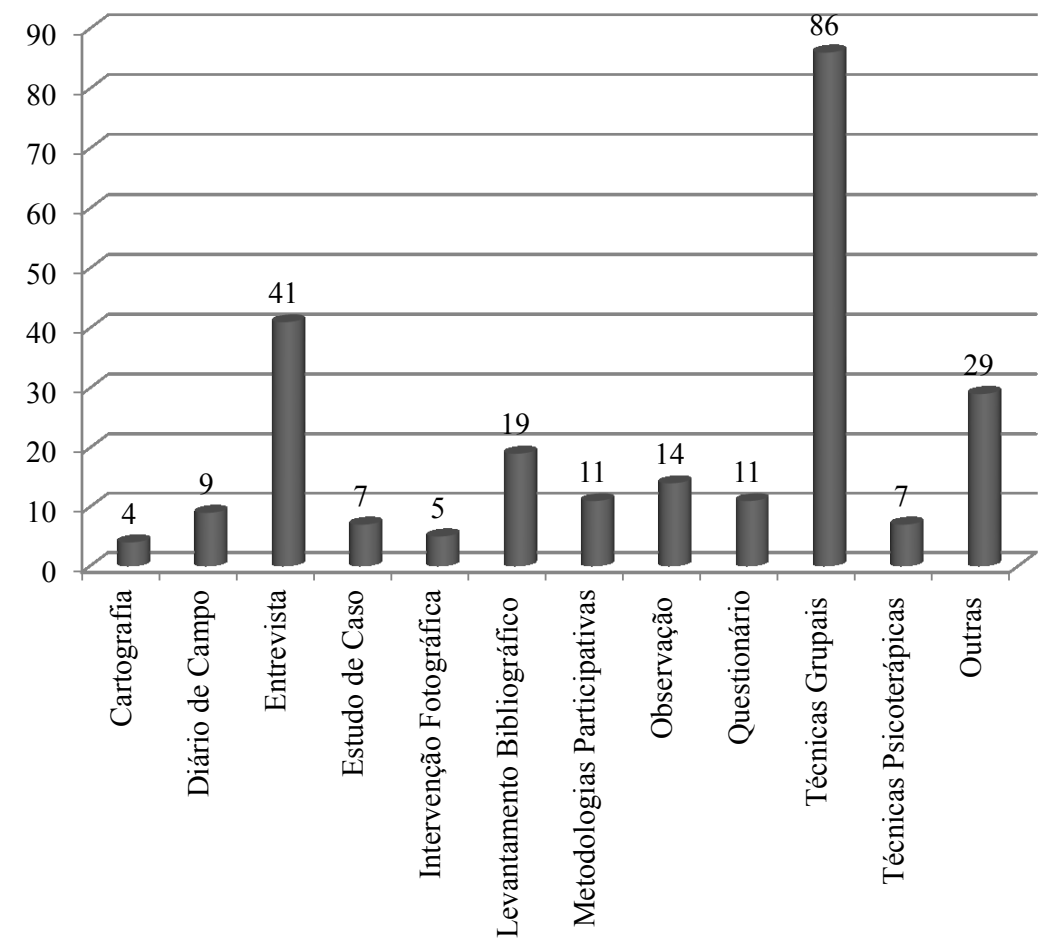


referências citadas, de modo que, em alguns casos, quando o trabalho fazia menção a mais de um procedimento, todos foram considerados. Assim, o total de procedimentos apresentados refere-se à quantidade total de menções a procedimentos (243 registros).

Nota-se que as Técnicas Grupais aparecem como os procedimentos metodológicos mais mencionados e utilizados nos relatos analisados.

Como já apontado, em decorrência da ausência de "definições" formais para o termo intervenção, mostraremos, na Figura 6, a análise realizada a partir do método ALCESTE a fim de identificarmos os possíveis significados do termo intervenção no nosso corpus.

Figura 6 - Porcentagem de UCE contida em cada classe, as principais formas reduzidas de palavras relacionadas a cada uma das classes, com o $Q^{2}$ de associação, e os títulos dados por nós às classes

\begin{tabular}{|c|c|c|c|}
\hline & \multicolumn{2}{|c|}{$\begin{array}{l}\text { Total de UCE Classificadas } \\
915 \text { UCE }\end{array}$} & \\
\hline $\begin{array}{c}\text { Classe } 1 \\
232 \text { UCE - } 25,00 \%\end{array}$ & $\begin{array}{c}\text { Classe } 3 \\
97 \text { UCE - } 11,00 \%\end{array}$ & $\begin{array}{c}\text { Classe } 2 \\
223 \text { UCE - } 24,00 \%\end{array}$ & $\begin{array}{c}\text { Classe } 4 \\
363 \text { UCE - 40,00\% }\end{array}$ \\
\hline
\end{tabular}

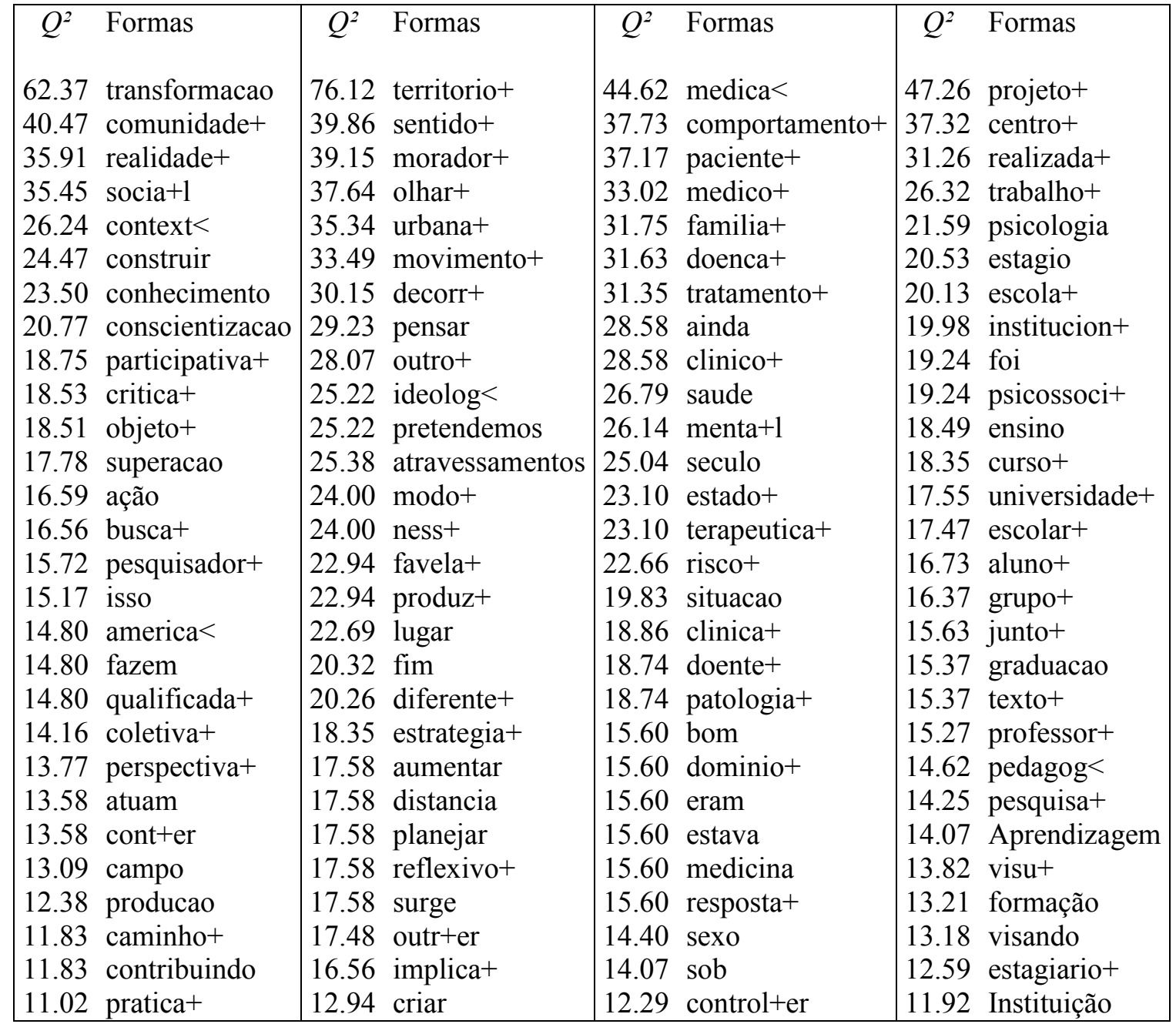

\begin{tabular}{|l|l|l|l|} 
Para quê intervir & Onde intervir & Como não intervir & Formar para intervir \\
\hline
\end{tabular}


Chegamos a esse conjunto de classes e formas reduzidas a partir da leitura realizada pelo ALCESTE, conforme já explicitado. O programa produziu uma lista de formas reduzidas características de cada classe e relacionou tais classes segundo o grau de proximidade existente entre essas formas (coocorrência). Quer dizer, quanto mais próxima uma classe estivesse de outra classe, mais elas falariam de um modo articulado acerca de determinado objeto, no nosso caso, o termo intervenção. Por sua vez, quanto maior a distância entre tais classes, menor seria a coocorrência das formas reduzidas características dessas duas classes. No nosso caso, podemos afirmar que houve uma maior aproximação do vocabulário das classes 01 e 03 e das classes 02 e 04, não havendo, entretanto, coocorrência considerável do vocabulário desses dois subconjuntos.

É importante informar que os títulos acima utilizados para nomear as classes resultantes da análise realizada pelo ALCESTE foram elaborados a partir das formas reduzidas já mencionadas e de uma lista gerada pelo programa com as UCEs características de cada classe. Essas UCEs vieram acompanhadas pelo $Q^{2}$, cuja função foi indicar o grau de associação da UCE à classe, de modo que, quanto maior o $Q^{2}$, mais característica da classe foi a UCE apresentada.

\section{Discussão dos dados e algumas considerações}

Embora existam, como apontamos na introdução, relatos que indiquem uma possível substituição do modelo de intervenção individual por um modelo de intervenção social na prática profissional do psicólogo brasileiro (Gondim, Bastos, \& Peixoto, 2010), assim como uma busca por novas formulações teóricas, métodos de trabalho e modos de inserção profissional na própria psicologia social (Souza \& Souza, 2009), quando analisamos os relatos que se referem à intervenção nos anais dos Encontros Nacionais da ABRAPSO de 2007, 2009 e 2011, encontramos um quadro diferente.

Em relação à substituição do modelo de intervenção individual por um modelo de intervenção social, podemos assinalar que, conquanto seja amplamente veiculada uma mudança de perspectiva na área, decorrente do processo de reformulação interna ocorrido a partir da década de 1950 e cujas repercussões se concretizaram no desenvolvimento de uma nova psicologia social voltada à transformação social e à prática (Camino \& Torres, 2011; Farr, 1998; Ferreira, 2011), os dados nos revelam um fenômeno interessante: dos 1.422 trabalhos consultados, apenas $260(18,28 \%)$ dizem respeito à intervenção propriamente dita. Era de se esperar uma quantidade maior de trabalhos enfocando esse tipo de ação.
Já quanto à busca de novas formulações teóricas, métodos de trabalho e modos de inserção profissional, podemos identificar, a partir dos relatos analisados, que há, sim, uma ampliação de objetos, aspectos metodológicos e espaços/locais, haja vista a diversidade desses elementos nos relatos. Tal ampliação, todavia, não se mostra tão significativa quando consideramos, por exemplo, que apenas 35 dos 260 trabalhos analisados (13,46\%) são dedicados a formulações teóricas que, de alguma forma, problematizam a intervenção em psicologia social. Nesse sentido, podemos dizer que a reflexão sobre os aspectos teóricos e metodológicos relativos à intervenção ainda carece de maior investimento da área, conforme já identificado também por Mayorga, Nascimento, Pinto e Pinto (2011).

Afinal, se a intervenção tem sido apontada como um aspecto fundamental para uma nova perspectiva em psicologia social, por que essa importância não aparece em relatos e formulações teóricas e metodológicas desenvolvidas pela própria área? Podemos afirmar, a partir do contexto acima apresentado, que parece haver um discurso em torno da importância da intervenção para a psicologia social que não se concretiza no material que analisamos.

Os dados exibidos neste relato apontam a formação como objeto de preocupação. Conforme foi possível observar na classe 04 originada na Análise ALCESTE, a formação acadêmica é apontada como sendo a adequada para o desenvolvimento de uma perspectiva dedicada à intervenção. A constituição dessa classe das formas reduzidas formação, pesquisa, estágio, ensino, universidade, instituição, dentre outros, indica o valor dado à produção de conhecimento de modo institucionalizado, formalizado e localizado para a intervenção.

Outro aspecto que merece destaque relacionase ainda aos limites da formação para a intervenção e diz respeito à dificuldade de superação do modelo clínico (médico) de atendimento individual apontado por Gondim, Bastos e Peixoto (2010). Esses limites na formação, cujas origens podem ser localizadas no desenvolvimento metodológico da psicologia social como uma ciência experimental e individualizante, cujas implicações manifestam-se diretamente na construção da identidade profissional do psicólogo brasileiro, também aparecem como objeto de preocupação em nosso estudo. Mais uma vez, a partir da Análise ALCESTE, especialmente da classe 02, podemos verificar uma referência explícita ao saber médico como aquele a ser abandonado. A negação do modelo clínico, biológico, psicopatologizante e individualizante é considerada, nos textos analisados, como fundamental para o desenvolvimento de uma perspectiva dedicada à intervenção. 
A partir disso, podemos localizar uma coerência entre o que tem sido identificado por alguns estudos (Gondim, Bastos, \& Peixoto, 2010; Souza \& Souza, 2009) como problemático para o desenvolvimento de uma perspectiva voltada à intervenção e o conjunto de dados analisados neste estudo. A demanda presente nos relatos de que a formação norteie a construção de conhecimentos a serem colocados em prática nos processos de intervenção, bem como a demanda pela construção de um novo olhar, diferente do olhar médico, constituíram os aspectos relativos à fundamentação para o desenvolvimento de uma perspectiva prática, conforme o segundo bloco originado na Análise ALCESTE.

Dito isso, podemos afirmar que parte considerável da produção por nós analisada continua vinculada quase que exclusivamente à academia, à universidade. Este aspecto possivelmente justifica a expressiva quantidade de trabalhos analisados e categorizados como sendo de pesquisa, a despeito de tratar-se de um conjunto de relatos referentes à intervenção.

Parece haver, assim, um interesse relacionado à intervenção tanto em trabalhos de pesquisa quanto em trabalhos práticos. Nesse aspecto, não é possível pensar esse conjunto de dados sem chegarmos a um desdobramento lógico em torno da intervenção acompanhada da pesquisa: trata-se de uma atuação pautada na formação adequada aos moldes acadêmicos.

Se antes se falava que não havia pesquisa sem intervenção e se questionava o não desdobramento das pesquisas em transformação social, a partir dos relatos analisados é possível salientar que, para os autores, não há intervenção sem pesquisa, ou, ao menos, não deveria haver. Em suma, não é possível fazer sem antes conhecer. Não se trata, todavia, de pesquisar para intervir, mas de fazer com que esses processos aconteçam juntos, de tal forma articulados que um seja potencializador do outro.

As produções analisadas indicam também outra tendência mantida nos relatos, que diz respeito à busca pela construção de conhecimentos para a transformação social. A procura por uma aproximação entre a prática de pesquisa e a intervenção em psicologia social com os diversos setores da sociedade pode ser verificada na classe 01 originada na Análise ALCESTE e nomeada por nós como Para quê intervir. A presença de formas reduzidas como transformação, realidade, construir, conscientização, participativa, ação, busca, dentre outras, mostra um interesse explícito em continuar com o propósito "original" de transformação das problemáticas enfrentadas pela sociedade brasileira, de forma crítica e participativa (Lane \& Bock, 2003; Tatsch, Guareschi, \& Baumkarten, 2009).
As problemáticas identificadas na origem do desenvolvimento dessa perspectiva encontravam-se localizadas especialmente nas comunidades, favelas, periferias, enfim, no contexto urbano. Tal tendência também é observada nos relatos analisados, cuja presença de formas reduzidas como território, urbana, favela, cidade, dentre outras, na classe 03 originada na Análise ALCESTE, permite-nos afirmar que a realidade que se pretende transformar hoje é a realidade próxima, dos territórios próximos, das cidades nas quais se vive. Há, assim, uma coerência também no que toca ao objetivo de transformar aliado ao espaço que se pretende transformar, a realidade próxima, que constituíram em nossa análise os aspectos relativos à prática conforme o primeiro bloco originado na Análise ALCESTE.

A análise do conjunto do que foi aqui apresentado nos possibilita identificar a intervenção em psicologia social, segundo os textos analisados, como um processo que parte de uma formação acadêmica específica, em psicologia social, para transformar a realidade social próxima (urbana) com ações não baseadas no paradigma médico (biológico), mas pautadas em um novo olhar sobre a realidade que se pretende transformar.

Compreendemos ainda, a partir de uma apreciação geral do conjunto de relatos analisados, que, apesar de algumas já apontadas contradições entre o que é difundido e o que é identificado na prática nessas pesquisas, os Encontros Nacionais da ABRAPSO têm se configurado como espaços de diálogos acerca da diversidade da realidade brasileira. A expressiva variedade de problemáticas colocadas em discussão e a diversidade de contextos e alvos abordados revelam uma preocupação da área com as novas questões vivenciadas pela sociedade brasileira.

Vale destacar, no entanto, a manutenção de trabalhos que abordam, em especial, duas temáticas historicamente identificadas como problemáticas pela sociedade brasileira, quais sejam: Saúde e Educação. Quando analisamos os espaços/locais escolhidos para as intervenções, temos uma coerência de interesses, haja vista as Instituições de Educação e as Instituições de Saúde também sobressaírem-se (um total de 138 relatos, sendo 75 relativos às Instituições de Saúde e 63 às Instituições de Educação) em relação aos outros espaços/locais (122 relatos divididos entre 14 diferentes espaços/locais, representando uma média de quase 9 para cada tipo).

O relevante número de trabalhos de intervenção concentrados nesses dois eixos (Saúde e Educação) é acompanhado por um relevante número de trabalhos concentrados tanto nos espaços/locais quanto nos alvos 
principais a eles referentes. Este aspecto observado durante todo o período analisado indica não só o quanto essas duas temáticas ainda demandam ações diversas dos mais diferentes setores da sociedade brasileira, que, inclusive, extrapolam o papel a ser desempenhado pelo poder público, mas também o quanto a psicologia social abrapsiana mantém a atenção voltada para as demandas sociais já presentes no seu contexto de origem.

Por fim, outro aspecto que também sofreu pouca variação ao longo do período analisado diz respeito à predominância de trabalhos de pesquisa, assim como de trabalhos práticos relacionados à intervenção, sendo os primeiros mais frequentes e os segundos notadamente mais diversificados. Considerando a predominância de trabalhos de pesquisa e de trabalhos práticos, identificamos uma grande coerência entre objetivo e tipo de trabalho, devido à também predominância do objetivo "conhecer" nos trabalhos de pesquisa, bem como do objetivo "fazer" nos trabalhos práticos. Podemos afirmar que essa tendência está relacionada às funções tradicionais que ligam "conhecer" à pesquisa e "fazer" à prática. Tal tendência contraria, contudo, um interesse inicial, já elucidado, em associar essas duas perspectivas e em torná-las parte de um mesmo processo, visto que a relação entre conhecer e fazer sempre esteve no foco das discussões que buscavam caracterizar e delimitar a psicologia social brasileira como uma ciência como práxis (Guareschi \& Dhein 2009; Maraschin, 2004; Sudbrack, 2009).

Por outro lado, se tomarmos como referência os objetivos, poderemos identificar uma predominância de trabalhos com o objetivo "fazer", contrariando a predominância de trabalhos de pesquisa. Tal aspecto aponta o destaque dado ao "fazer", independentemente do tipo de trabalho em questão, mesmo nos casos em que o trabalho tem como característica forte a análise ou o conhecimento de algo. Temos, desse modo, no que se refere à intervenção, um objetivo primordial: fazer algo. Este objetivo está na origem do que estamos aqui chamando de uma perspectiva voltada à intervenção em psicologia social e parece sustentá-la na atualidade da psicologia social abrapsiana, de maneira que o compromisso é ainda com a atuação, com a aplicação dos conhecimentos como alternativa de transformação.

\section{Considerações finais}

A partir deste estudo, foi possível identificar, na psicologia social que tem sido construída na realidade brasileira hoje, aspectos relativos à prática, no que diz respeito ao para quê intervir e onde intervir, assim como aspectos relativos à fundamentação no que concerne ao modo como não intervir e à formação necessária para intervir. Além disso, identificamos algumas continuidades, bem como algumas descontinuidades em relação à proposta inicial abrapsiana de uma perspectiva voltada à intervenção. Chegamos ainda a um possível "conceito" para intervenção, "conceito" este construído a partir do conjunto dos trabalhos analisados.

Apesar disso, devido às limitações deste estudo, restrito a uma pesquisa documental em nível de mestrado, e, por isso, de reduzido alcance e tempo, avaliamos que muitos outros aspectos merecem ainda ser investigados, especialmente no que tange a outras fontes de referência, assim como a possíveis compreensões relacionadas às diferenças ocorridas no tocante à proposta inicial da ABRAPSO e o que pode ser verificado na atualidade dos trabalhos analisados. Vale ressaltar que, tratando-se essa investigação de um estudo exploratório e, por isso, de caráter mais descritivo, não foi possível uma análise aprofundada do contexto de produção dos textos analisados. Nesse sentido, nosso intuito, neste primeiro momento, foi apresentar um mapeamento de tais produções. Posteriormente, pretendemos analisar o contexto político e histórico das referidas produções.

Por fim, avaliamos também que um segundo trabalho que procurasse identificar os significados e usos da intervenção, ouvindo diretamente psicólogos sociais de diversas regiões de nosso país, nos permitiria ainda avançar na compreensão de como esses profissionais estão construindo "novos" olhares para a realidade brasileira.

\section{Nota}

O ALCESTE transformou os fragmentos de texto (todas as frases com presença do termo intervenção) em Unidades de Contexto Inicial - UCIs (total de 260 UCIs, correspondente ao total de trabalhos analisados). Essas UCIs foram posteriormente transformadas em Unidades de Contexto Elementar-UCEs, a partir de critérios relativos a tamanho do texto, especificamente ao número de palavras analisadas e pontuação. Tais UCEs possibilitaram o estabelecimento de matrizes de coocorrência a partir das quais o programa procedeu à classificação do corpus. Essa classificação foi apresentada em formato de listas de formas reduzidas associadas a contextos que corresponderam às classes formadas e possibilitaram a identificação das UCEs características de cada uma dessas classes, que, por sua vez, puderam ser interpretadas como conteúdo, funcionamento e/ou representação (Nascimento \& Menandro, 2006). Mais informações técnicas relativas ao programa ALCESTE encontram-se disponíveis em Oliveira, Gomes e Marques, 2005; Kronberger e Wolfgang, 2002; Nascimento e Menandro, 2006. 


\section{Referências}

Bardin, L. (1977). Análise de Conteúdo. Lisboa: Edições 70.

Bauer, M. W. (2002). Análise de conteúdo clássica: uma revisão. In W. B. Martin \& G. George (Eds.), Pesquisa qualitativa com texto, imagem e som (pp. 189-217). Petrópolis, RJ: Vozes.

Bomfim, E. M. (2003). Psicologia social no Brasil. Belo Horizonte: Edições do Campo Social.

Camino, L. \& Torres, A. R. R. (2011). Origens e desenvolvimento da Psicologia Social. In L. Camino, A. R. R. Torres, \& M. E. O. Lima (Orgs.), Psicologia Social: temas e teorias (pp. 2399). Brasília, DF: Technopolitik.

Farr, R. M. (1998). As raizes da psicologia social moderna. Petrópolis, RJ: Vozes.

Ferreira, M. C. (2011). Breve história da moderna psicologia social. In C. V. Torres \& E. R. Neiva (Orgs.), Psicologia social: principais temas e vertentes (pp. 13-30). São Paulo: Artmed.

Guareschi, N. M. F. \& Dhein, G. (2009). Formação em psicologia: história, cultura e política. In D. T. Tatsch, N. M. F. Guareschi, \& S. T. Baumkarten (Orgs.), Tecendo relações $e$ intervenções em psicologia social (pp. 64-73). Porto Alegre: ABRAPSO SUL.

Gondim, S. M. G., Bastos, A. V. B., \& Peixoto, L. S. A. (2010). Áreas de atuação, atividades e abordagens teóricas do psicólogo brasileiro. In A. V. B. Bastos \& S. M. G. Gondim (Orgs.), O trabalho do psicólogo no Brasil (pp. 174-199). Porto Alegre: Artmed.

Kronberger, N. \& Wolfgang, W. (2002). Palavras-chave em contexto: análise estatística de textos. In M. W. Bauer \& G. Gaskell (Orgs.), Pesquisa qualitativa com texto, imagem e som: um manual prático (pp. 416-441). Petrópolis, RJ: Vozes.

Lane, S. T. M. \& Bock, A. M. B. (2003). ABRAPSO - uma história da Psicologia Social enquanto práxis. In A. M. JacóVilela, M. L. Rocha, \& D. Mancebo (Orgs.), Psicologia Social: relatos na América Latina (pp. 145-155). São Paulo: Casa do Psicólogo.

Maraschin, C. (2004). Pesquisar e intervir. Psicologia \& Sociedade, 16(n. spe.), 98-107.

Mayorga, C., Nascimento, A. R. A., Pinto, G. P., \& Pinto, T. P. S. (2011). Psicologia social em Minas: contexto sociopolítico de produção na Psicologia \& Sociedade. Psicologia em pesquisa, 5(2), 135-145.

Moreira, M. I. C. (2007). A formação em psicologia social. In C. Mayorga \& M. A. M. Prado (Orgs.), Psicologia Social: articulando saberes e fazeres (pp. 55-62). Belo Horizonte: Autêntica.

Nascimento, A. R. A. \& Menandro, P. R. M. (2006). Análise lexical e análise de conteúdo: uma proposta de utilização conjugada. Estudos e Pesquisa em Psicologia, 6(2), 72-88.

Neiva, K. M. C. (2010). Intervenção psicossocial: aspectos teóricos, metodológicos e experiências práticas. São Paulo: Vetor.

Neiva, E. R. \& Torres, C. V. (2011). Psicologia Social no Brasil: uma introdução. In C. V. Torres \& E. R. Neiva (Orgs.), Psicologia Social: principais temas e vertentes (pp. 31-57). São Paulo: Artmed.

Oliveira, D. C., Gomes, A. M. T., \& Marques, S. C. (2005). Análise estatística de dados textuais na pesquisa das representações sociais: alguns princípios e uma aplicação ao campo da saúde. In M. S. S. Menin \& A. M. Shimizu (Orgs.),
Experiência e representação social: questões teóricas e metodológicas. São Paulo: Casa do Psicólogo.

Souza, L. C. G. \& Souza, E. A. (2009). O lugar da psicologia social na formação dos psicólogos. Psicologia \& Sociedade, 21(3), 383-390.

Sudbrack, M. F. O. (2009). Integrando pesquisa, intervenção e formação em psicologia clínica. In D. T. Tatsch, N. M. F. Guareschi, \& S. T. Baumkarten (Orgs.), Tecendo relações e intervenções em psicologia social (pp. 110-129). Porto Alegre: ABRAPSO SUL.

Tatsch, D. T., Guareschi, N. M. F., \& Baumkarten, S. T. (2009). Tecendo relações e intervenções em psicologia social. Porto Alegre: ABRAPSO SUL.

Vala, J. (2003). A análise de conteúdo. In A. S. Silva \& J. M. Pinto (Orgs.), Metodologia das Ciências Sociais (12 ${ }^{\mathrm{a}}$ ed., pp. 101-128). Porto: Afrontamento.

\section{Agradecimento}

À Agência de fomento: CAPES - Bolsa DS.

Submissão em: 26/06/2013

Revisão em: 13/03/2013

Aceite em: 07/07/2014

Leidiane Pereira Lopes é mestre em Psicologia Social pela Universidade Federal de Minas Gerais - Bolsista

CAPES. Possui graduação em Psicologia pela Pontifícia Universidade Católica de Minas Gerais. Atualmente é Analista de Políticas Públicas na Prefeitura de Belo Horizonte e Docente na Pós-Graduação em Intervenção Psicossocial no Contexto das Políticas Públicas no Centro Universitário Una. Endereço para correspondência: Centro Universitário Uma. Av. João Pinheiro, 515, Funcionários Belo Horizonte/MG, Brasil. CEP 30130-180 E-mail: leidipsicologia@yahoo.com.br

Adriano Roberto Afonso do Nascimento é mestre e doutor em Psicologia pela Universidade Federal do Espírito Santo (2004). Atualmente é professor adjunto do Departamento de Psicologia da Universidade Federal de Minas Gerais e professor-orientador do Programa de Pós-Graduação em Psicologia/FAFICH/UFMG. E-mail: nascimentopsi72@gmail.com 